\title{
Ağır Metaller ile Kirlenmiş Toprağın İyileştirilmesinde Vetiver Grass (Vetiveria zizanioides (Linn.) Nash) ve Solucanların Kullanılması
}

\author{
Yasemin CINDIK AKINCI ${ }^{1 *}$, Turan YÜKSEK ${ }^{2}$, Öner DEMIREL \\ ${ }^{1}$ Karadeniz Teknik Üniversitesi, Orman Fakültesi, Peyzaj Mimarlığı Bölümü, 61080, Trabzon, Türkiye. \\ ${ }^{2}$ Recep Tayyip Erdoğan Üniversitesi, Güzel Sanatlar Tasarım ve Mimarlık Fakültesi, Peyzaj Mimarlığı \\ Bölümü, 53100, Rize, Türkiye. \\ *e-mail: yasemincindik@gmail.com \\ Öz \\ Dünya üzerindeki yaşamın kalitesi çevrenin kalitesi ile ayrılmaz bir bütündür. Günümüzde organik ve inorganik \\ kirlenme çevre ve insan sağlığı üzerinde önemli sorunlar meydana getirmektedir. Kentleşmenin artması ve \\ sanayinin gelişmesi ile insan odaklı ağır metal kullanımı giderek artmıştır. Ağır metaller toprak ve suya karışarak \\ besin zincirini üzerinde olumsuz etkilere sahiptir. Son yıllarda kirlenmiş toprak ve suyun iyileştirilmesi için güçlü \\ ve etkili teknikler geliştirilmiştir. Ayrıca bu tekniklerin yerinde, etkili, ekonomik ve çevre dostu olması önemlidir. \\ Bu nedenle fitoremediasyon ve biyoremediasyon teknikleri ile yapılan çalışmalar ve literatürlerde önemli yer \\ tutmuştur. Bu çalışma ile su, toprak ve çevre üzerinde ağır metallerin uzaklaştırılması faaliyeti olarak kullanılan \\ fitoremediasyon ve biyoremediasyon konuları hakkında bilgi verilecektir. Ayrıca dünyaca bilinen ve \\ fitoremediasyon bitkisi olan Vetiver çimi (Vetiveria zizanioides (Linn.) Nash) ağır metal kirlenmesini gidermesi \\ için kullanımından ve biyoremediasyon organizması olan bazı solucanların ağır metal kirleniminin \\ temizlenmesinde kullanılabilirliği tartışılmıştır.
}

Anahtar Kelimeler: Vetiver grass, solucanlar, biyoremediasyon, fitoremediasyon

\section{Remediation Contaminated Soil by Heavy Metal: Vetiver Grass (Vetiveria zizanioides (Linn.) Nash) and Earthworms}

\begin{abstract}
Quality of life and environment of the world are inseparable. Nowadays, organic and inorganic contamination produces major problems on the environment and human health. People-oriented heavy metal usage has increased due to urbanization and industrial development. Heavy metals have negative impacts on the soil and water, blending into the food chain. Powerful and effective techniques for treating contaminated soil and water have been developed in recent years. It is important that these techniques are appropriate, effective and ecofriendly. Therefore phytoremediation and bioremediation techniques in the studies and literatures take an important place. With this study, phytoremediation and bioremediation will be informed about topics that used as removal of heavy metals activities on water, soil and environment. In addition, worldwide known and phytoremediation plants Vetiver grass (Vetiveria zizanioides (Linn.) Nash) were discussed to use for removal of heavy metal contamination. Then bioremediation organisms earthworms were discussed to use for purified of heavy metal contamination.
\end{abstract}

Keywords: Vetiver grass, earthworms, bioremediation, phytoremediation

\section{Giriş}

21. yüzyılda başta gelişmekte olan ülkelerde olmak üzere bir yandan dünya nüfusu, diğer yandan şehirli nüfusu hızlı bir şekilde artmaktadır. 1950'de dünya nüfusunun \% 30'u kentlerde yaşarken, 2010'da bu oranın \% 50’yi aştığı belirtilmektedir (Danış, 2016). Ülkemizde de dünyadakine paralel bir 
durum söz oranın \% 50’yi aştığı belirtilmektedir (Danış, 2016). Ülkemizde de dünyadakine paralel bir durum söz konusudur.

1950 yılında ülkemizdeki şehirli nüfus toplam nüfusun \%25'i iken, 2012 yılında şehirli nüfus oranı \%77 düzeyine çıkmıştır (Yılmaz, 2015). Sanayileşmenin kentsel alanların yakın çevresinde yoğunlaşması, kırsal alandaki yaşam standartlarının istenilen düzeyde iyileştirilememesi ve insanların daha iyi yaşam koşullarına sahip olma arzusu, nüfusun kırsaldan şehirlere doğru göç etmesinde çok önemli rol oynamaktadır. Hızlı, plansız kentleşme ve sanayileşme, hızla artan trafik, gerekli önlemler alınmadan işletilen madenler, yanlış arazi kullanımı, tarım arazilerinde artan kimyasal gübre ve pestisit uygulamaları, toprak erozyonu dünya genelinde olduğu gibi ülkemizdeki çevre kirliliğine neden olmaktadır. Çevremizi kirleten ve yaşam kalitemizi düşüren, dahası insanların hastalanmasına neden olan kirleticilerin başında; bünyesinde ağır metal barındıran atık maddeler gelmektedir. Ağır metal içeren kirleticiler kalıcı olarak doğada toprak üzerinde ya da içerisinde birikir. Periyodik cetvelin üçüncü ya da daha yüksek periyodundaki elementler $(\mathrm{Cd}, \mathrm{Cr}, \mathrm{Cu}, \mathrm{Hg}, \mathrm{Pb}, \mathrm{Ni}, \mathrm{Sn}, \mathrm{Zn}$ vb) ağır metaller olarak adlandırılmaktadır (Şener, 2010). Ağır metaller toprağı aktif halde kullanan insanların sağlığı açısından tehdit iken bu metaller beslenme zincirinde yer alan tüm canlılara zarar vermektedir. Ağır metallerin ekosistemde hava, toprak, su, bitki ve hayvanlar üzerinde ciddi seviyede olumsuz etkileri vardır. Ekosistemin önemli kıt kaynaklarından olan su ve toprağın plansız ve bilinçsizce kullanımı çevresel kirliliğini daha da artırmaktadır. Su ve toprak et ve tırnak gibidir. Birinin kirlenmesi sonucunda diğeri de kirlenmektedir.

Tarım alanlarındaki hatalı gübre uygulamaları (gübre çeşidi, gübreleme zamanı ve gübre miktarının doğru tespit edilmemesi, vb), hastalık ve zararlılarla mücadele de gelişigüzel pestisit kullanımı, kirli suların arıtılmadan sulama suyu olarak kullanılması, ağır metallerce zengin endüstriyel atıkların arıtılmadan dış ortama deşarj edilmesi veya depolanması, maden ocaklarındaki ağır metal içeren işletme atıkları ve kirlenmiş sızıntı sularının arıtılmadan dış ortama bırakılması veya olduğu yerde hiçbir iyileştirme yapılmadan terk edilmesi sonucu toprak ve su kaynakları kirletilmektedir.

Kirlenen su ve toprak kaynaklarının temizlenmesi ve kirlilik sorunun giderilmesi kaçınılmazdır. Zira her iki kaynak sürdürülebilir kaliteli bir yaşam için elzem olup dünya genelindeki miktarları kısıtlı düzeydedir. Ağır metal içeren toprakların ve suyun temizlenmesinde çeşitli teknolojik ve doğal yöntemler kullanılmaktadır. Ancak bu yöntemlerin çoğu yoğun iş gücü gerektiren ve masraflı kazılar, atık depolama ve süzdürme ve arıtma teknolojileridir (Salt vd., 1995). Bu yöntemler genel olarak çok pahalı ve bazen de uygulanamayabilir.

Ağır metallerce kirlenmiş ortamların temizlenmesi konusunda farklı bilim dalına mensup araştırmacılar çalışmalarına devam etmektedirler. Türkiye'de çeşitli bilim dallarında (peyzaj, orman, ziraat, toprak, biyoloji, tıp, maden vb.) ağır metallerin çevresel etkileri üzerine birçok yayın ve araştırma yapılmıştır (Baş ve Demet, 1992; Okcu vd., 2009; Özay ve Mammadov, 2013, Kocaer ve Başkaya, 2003; Hamutoğlu vd., 2012; Aybar vd., 2015; Yurdakul, 2015). Dünya genelinde (Evanko and Dzombak, 1997; Garbisu and Alkorta, 2003; Usman et al., 2006; Marques et al., 2009; Damodaran et al., 2011; Montinaro et al., 2012) ağır metalli toprakların iyileştirilmesi konulu çalışmaları vardır.

Kirlenmiş toprak ve suyu kaynaklarının iyileştirilmesinde: Fiziksel ve kimyasal teknikler, Biyoremediasyon ve fito-remediasyon teknikleri çok yoğun bir şekilde kullanılmaktadır (Khan, 2003).

\section{Materyal ve Yöntem}

Çalışmada genelden özele doğru bir çerçeve çizildi ve üç aşamalı olarak ele alındı. İlk aşamada ağır metallerin su ve toprak üzerindeki çevresel etkileri üzerinde duruldu. Kuramsal olarak gelişimsel bir dayanak ele alındı ve literatür kaynaklarına yer verildi.

İkinci aşamada ise toprağın ağır metallerden temizlenmesi için kullanılan yöntemlerden canlı organizmaların kullanıldığı biyo-remediasyon ve bitkilerin kullanıldığı fito-remediasyon üzerinde duruldu. Ayrıca çalışmada toprakta biriken ağır metallerin giderilmesi için kullanılan Vetiver grass bitkisi ve solucanların kullanılabilirliği irdelenmeye çalışıldı. Bu aşamada çalışılan ortam ve koşullarda geçerlik ve kesinlik içeren literatür bilgilerine yer verildi. 
Üçüncü aşamada ise Türkiye'de konu ile ilgili yapılmış çok fazla çalışma olmadığı için güçlü ve zayıf yönlerinin bölge yöre koşulları altında değişebileceğine ve özgün çalışmaların ortaya çıkabileceğine dair sonuçlar ortaya konuldu.

\section{Bulgular ve Tartışma}

\subsection{Toprak Kirleticiler}

Toprak kirliliği, bitki büyümesi ve hayvan sağlığı üzerinde olumsuz etkilere sahip; kalıcı zehirli bileşikler, kimyasal maddeler, radyoaktif maddeler ya da hastalığa neden olan ilaçların topraklarda birikmesi olarak tanımlanır (Okrent, 1999).

Toprak kirlenmesinin çok çeşitli yolları vardır. Arazi kullanımlarında toprağa giren kirleticiler, kötü depolamadan kaynaklı farklı yağ ve yakıtların zemin üzerinden toprağa karışması, böcek ilaçlarının ve kimyasal gübrelerin aşırı uygulanması bunlardan bazılarıdır.

Kirletici kaynakların en önemlisi insan faaliyetleri sonucu meydana gelen kirliliktir. İnsan faaliyetleri sonucu meydana gelen kirlilikte evsel, zirai ve endüstriyel nitelikli olarak üç kategoriye ayrılabilir (Türkoğlu, 2006). İnsan kaynaklı toprağın ağır metal kirlenmesi doğal olayların yanı sıra; madencilik, döküm işlemleri, tarım kaynaklı olmaktadır. Kimya ve metalürji endüstrisi çevreyi kirleten en önemli ağır metal kaynaklarıdır (Suciu et al., 2008). Bu metallerce kirletilmiş ortamların temizlenmesinde kullanılan yöntemler Çizelge 1 de sunulmuştur.

Çizelge 1. Geleneksel metal uzaklaştırma yöntemleri ile bu yöntemlerin avantaj ve dezavantajları (ileri, 2000; Hamutoğlu vd., 2012).

\begin{tabular}{|c|c|c|}
\hline METOD & AVANTAJ & DEZAVANTAJ \\
\hline $\begin{array}{l}\text { Kimyasal } \\
\text { Çöktürme ve } \\
\text { Filtrasyon }\end{array}$ & $\begin{array}{l}\text { Basit } \\
\text { Ucuz }\end{array}$ & $\begin{array}{c}\text { Yüksek konsantrasyonlarda zor } \\
\text { ayrılma } \\
\text { Etkin değil } \\
\text { Atık çamur Oluşumu }\end{array}$ \\
\hline $\begin{array}{c}\text { Kimyasal } \\
\text { Oksidasyon ve } \\
\text { İndirgenme }\end{array}$ & İnaktivasyon & Ortam Hassasiyeti \\
\hline İyon Değişimi & $\begin{array}{l}\text { Etkin Arıtım ve saf } \\
\text { atık metalin geri } \\
\text { kazanımı }\end{array}$ & $\begin{array}{l}\text { Partiküllere hassas ve } \\
\text { reçinelerin pahalı olması }\end{array}$ \\
\hline Buharlaştırma & Saf atık elde etme & $\begin{array}{l}\text { Fazla enerji gereksinimi } \\
\text { Pahalı olması } \\
\text { Atık çamur oluşumu }\end{array}$ \\
\hline Ters Osmos & $\begin{array}{l}\text { Geri dönüşüm için } \\
\text { saf atık eldesi }\end{array}$ & $\begin{array}{l}\text { Yüksek basınç } \\
\text { Membran boyutu } \\
\text { Pahalı olması }\end{array}$ \\
\hline Adsorpsiyon & $\begin{array}{l}\text { Sorbentlerin aktif } \\
\text { karbon kullanımı }\end{array}$ & Tüm metaller için uygulanması \\
\hline
\end{tabular}

\subsection{Fitoremediasyon}

Fitoremediasyon yeşil bitkilerin kullanılarak kirli tehlikeli atıkların ortamdan uzaklaştırımasıdır. Genel bir terim "Fitoremediasyon" Latin kökenli Remedium (düzeltmek veya bir kötülüğü ortadan kaldırmak için), Yunanca kökenli Phytos (bitki) kelimelerinden meydana gelmiştir (Cunnigham et al., 1996). Fitoremediasyon yaşayan bitkilerin bünyesel yeteneklerini kullanması ile in-situ (yerinde) iyileştirme 
teknolojisidir (Etim, 2012). Fitoremediasyon, kirlenmiş su ve ya toprağı iyileştirmek için bitkilerin (doğrudan ya da dolaylı olarak) kullanılmasıdır. Bu teknoloji çevresel kirleticilerin kaldırılmasını ele alan herkes tarafından kabul edilebilir, müdahalesiz, maliyeti ekonomik bir yol olarak ortaya çıkmıştır. Bitkiler organik ve inorganik kirletici birikmesine, organik kirletici maddelerin katalizlenmesine ve kök bölgesindeki organik kirletici maddelerin mikrobiyal bozulmasını teşvik etmek için kullanılabilir (Arthur et al., 2005). Fitoremediasyon ağır metal iyileştirmek için yenilikçi, ekonomik ve çevreyle uyumlu bir yöntem olarak kabul edilmektedir. Bu bitkilerin genellikle kökleri kirlenmiş toprağı ve suyu temizleyici özelliktedir. Ayrıca bazı bitkilerin de hava temizleyici özellikleri vardır. Metal fitoremediasyonun çeşitli alt kümeleri geliştirilmiştir (Çizelge 2).

Çizelge 2. Fitoremediasyon tekniklerinin kirletici çeşitlerine göre sınıflandırılması (Aybar vd., 2015).

\begin{tabular}{|c|c|}
\hline $\begin{array}{c}\text { Metal Kirleticilerde Kullanılan } \\
\text { Yöntemler }\end{array}$ & $\begin{array}{c}\text { Organik Kirleticilerde Kullanılan } \\
\text { Yöntemler }\end{array}$ \\
\hline Fitoekstraksiyon & Fitodegradasyon \\
\hline Rizofiltrasyon & Rizodegradasyon \\
\hline Fitostabilizasyon & Fitovolatilizasyon \\
\hline
\end{tabular}

\subsubsection{Fitoremediasyon avantaj ve dezavantajları}

Çeşitli organik ve inorganik bileşikler fitoremediasyon işlemi için uygundur (Henry, 2000; Moosavi and Seghatoleslami, 2013). Fitoremediasyonun büyük bir avantajı geleneksel iyileştirme yöntemlerine göre çoğu zaman daha ucuzdur (Pilon-Smits and Freeman, 2006). Fitoremediasyon in-situ (yerinde) veya ex-situ (ortam dışı) uygulamaları şeklinde kullanılabilir (Frick et al., 1999). Ancak, bu sistemin avantajları yanı sıra bazı dezavantajları da vardır. Bu iyileştirme bitkilerin köklenme derinliği ile sınırlı kalmaktadır. Bitkilerle iyileştirme uzun bir süreçtir, bu nedenden dolayı birkaç yıl ya da daha fazla sürebilir ve kirlenme tam kapasitede bertaraf edilmeyebilir (USEPA, 2000). Yerli olmayan, istilacı bitkilerin yoğun bir şekilde kullanımı biyoçeşitliliği olumsuz biçimde etkileyebilir. Kirlenmiş bitkilerin meyve, yaprak, kök vb gibi kısımlarının özellikle insan ve yaban hayatı tarafından tüketimi çok ciddi sağlık sorunlarına ve popülasyon dinamiklerinin bozulmasına neden olabilir. Fitoektrasyon sürecinden üretilen toplanmış bitki biyokütlesi tehlikeli atık olarak sınıflandırılabilir; bu nedenle bu atıkların uygun taşıma ve dikkatli bir şekilde bertaraf edilmesi gerekmektedir (Henry, 2000). Bu atıkların bertaraf edilmesi de ayrı bir zaman, işgücü ve maliyete neden olmaktadır. Bütün bunlar yöntemin dezavantajları arasındadır.

\subsubsection{Fitoremediasyon bitkileri: Vetiver grass}

Yeşil bitki bazlı sistemlerin kullanılarak ağır metallerin toprak, su ve taban çökellerinin temizlenmesi işlemine fitoremediasyon denir. Birçok geleneksel iyileştirme mühendisliği teknikleri ile karşılaştırıldığında, fitoremediasyon çeşitli yüzeysel kirletici maddelerin etkilerini gidermeyi amaçlayan yeni gelişen bir teknolojidir (Cunningham et al., 1996). Fitoremediasyon bitkilerin doğal işleyiş süreçlerinden yararlanmaktadır. Fitoremediasyon için bitki türleri kendi kök derinliği, kirletici ve toprak yapısına ve bölgesel iklime göre seçilir. Kök derinliği doğrudan kirlenmiş toprağın temizlenmesini etkilemektedir (EPA, 2001).

Ağır metaller ile toprağın kirlenmesi ve insan sağlığı üzerinde etkileri dünyada önemli bir sağlık sorunudur. Metalle kirlenmiş toprağın fitoremediasyonu esas olarak farklı iyileştirme mekanizmalarına göre üç farklı yaklaşımı vardır. Bunlar:

- Bitkilerin ekilip biçilebilir dokularından (sürgünler) ayıklanması ve konsantre edilmesiyle topraktaki metalleri çıkarmak için metal biriken bitkilerin kullanımı Fitoektrasyon,

- Metalleri hareketsiz kılmak ve topraktaki metallerin biyo yararlanımını azaltmak için bitkilerin kullanılması Phytostabilization,

- Topraktan metalleri yukarı çekmek, onları uçucu forma dönüştürmek, atmosfer içinde belirginleştirmek için bitkilerin kullanımı Phytovolatilization (Jian et al., 2011). 
Vetiver çimi (Vetiveria zizanioides (Linn.) Nash veya Chrysopogon zizanioides (L.) Roberty) bitkisi çok yıllık (perennial), ekolojik uyum yeteneği olan dayanıklı bir bitkidir. Olumsuz çevre koşullarında bile hızlı büyüyebilen ve farklı toprak tiplerine uyumlu olabilen özelliği sayesinde geniş alanlara adapte olabilmektedir. Ayrıca, sahip olduğu yoğun ve güçlü kök yapabilme yeteneği ile kuraklığa karşı dayanıklıdır (NRC, 1993; Cındık, 2012). Vetiver çimi bitkisi toprakta bulunan Al, Mn, As, Cd, Cr, Ni, Pb, $\mathrm{Hg}$, Se and Zn elementlerine yüksek tolerans gösterir (Truong and Baker, 1998; Truong et al., 2006). Bu karakteristik özelliği ile fitoremediasyon bitkisi olarak kullanılır. Köklerinin hızlı gelişim göstermesi, oluşturduğu yoğun toprak altı ve toprak üstü biyomass ile erozyonun önlenmesi, toprak ve su korumaya elverişli bir bitkidir.

Yapılan değişik çalışmalar incelendiğinde bitkinin ağır metallere dayanıklılığı birçok toprak ve su iyileştirme çalışmalarına konu olmuş ve dayanıklılı̆ı farklı araştırmacılar (Gerrard, 2008; Mudhiriza et al., 2015, Aksorn and Chitsomboon, 2013; Antiochia et al., 2007; Chen et al., 2000; Roongtanakiat and Chairoj, 2001) tarafından çalışılmıştır. Yapılan çalışmalarda Vetiver çimi bitkisinin hızlı büyümesi, geniş biyokütlesi, güçlü kök sistemi ve yüksek seviyede metallere toleransı olduğundan toprak stabilizasyonu için önemli bir bitki olduğunu belirtilmektedir (Lai and Chen, 2004; Roongtanakiat, 2009; Danh et al., 2009).

\subsection{Biyoremediasyon}

Biyoremediasyon kelimesi kirlenmiş toprakları ve suları temizlemek için mikro organizmaların kullanımını tanımlamak amaçlı bir terim olarak 1980'lerin başında bilim adamları tarafından ortaya atılmıştır. Ön ek olan "biyo" kelimesi canlı organizmalar tarafından gerçekleştirilen biyolojik süreci tanımlamaktadır. Remediasyon ismi ise tam bozulma yoluyla çevrenin temizlenmesi ya da mikrobiyal aktivite sonucu toksik maddelerin uzaklaştırılması olarak tanımlanır (Malik, 2006).

Biyoremediasyon, kirleticileri kaldırmak için mikroorganizma metabolizmasının kullanılmasıdır. Biyoremediasyon kendi oluşabilir (doğal zayıflama veya içsel biyoremediasyon) ya da ortam içerisindeki biyo yararlanımı artırmak için gübre ilave edilmesiyle ilgili olarak tetiklenebilir. Biyoremediasyon, doğal biyolojik aktiviteyi kullanarak zararsız çeşitli kirleticileri yok etme imkânı sunan bir seçenektir (Sharma, 2012). Biyoremediasyon kirlenen ortamını yönetmek ve kirlenmiş toprakları kurtarmak için etkili bir yönetim aracıdır. Biyoremediasyon kirlenmenin yerinde kullanılması (in-situ) ya da kirlenmenin özgün alandan kaldırıması (ex-situ) şeklinde kullanılabilir.

\subsubsection{Biyoremediasyon avantaj ve dezavantajları}

Biyoremidasyonun başarılı olması için, biyolojik iyileştirme yöntemlerinin doğru mikroorganizmalar ve doğru çevresel faktörlerle doğru yerde olmasına bağlıdır. Biyoremediasyon, yakılma ve depolama gibi geleneksel yöntemlere göre daha fazla avantajlar sunabilir (Boopathy, 2000). Avantajlarından bazıları; çeşitli organik ve inorganik bileşiklere çalışır, alanda ya da dışında yapılabilir; bakımı ve uygulaması kolay, diğer metodlara göre düşük maliyetli, estetik açıdan hoş ve çevre dostu, çöp depolama alanlarındaki atıkların miktarını azaltır. Dezavantajları ise, alanı iyileştirmek birkaç yıl sürebilir, iklim koşullarına bağlıdır (Chowdhury et al., 2012).

\subsubsection{Biyoremediasyon organizmaları: Solucanlar}

Ileri seviyede bozulmuş toprakların iyileştirilmesinde mühendislik ve ekolojik olmak üzere iki genel yaklaşım vardır. Biyoremediasyon işleminde toprağa aktif bir şekilde zarar veren organik kirleticileri yok etmek veya zararlarını azaltmak için organizmalardan faydalanılmaktadır. Bu uygulama şekli çevre ile uyumlu olduğu için aynı zamanda ekolojik bir uygulamadır. Mikroorganizmalar tarafından yürütülen biyoremediasyon çalışmalarına "mikro-remediasyon" adı verilmektedir. Son yıllarda toprakta bulunan ağır metallerin uzaklaştırımasında solucanlardan faydalanılmaktadır. Solucanlar kullanılarak topraktaki ağır metallerin uzaklaştııılması işlemine "Vermi-remidasyon" olarak adlandırılır (Sinha et al., 2009).

Belirgin bir şekilde, vermi-remidasyon solucanların yaşadıkları toprak ve toprak kalitesi bakımından bir gelişmeye yol açar. Solucanlar her gün büyük miktarda toprak yutar ve onları taşlıklarında taşlar ve kendi bağırsağında sindirir. Genel olarak solucanlar pek çok ağır metal içeren kimyasal kirleticilere, topraktaki organik kirleticilere toleranslıdır. Bu kirleticiler onların dokularında biyo-akümülatif (biyo 
birikimlidir) (Sinha et al., 2008). Toprak ortamında, bir solucanın etki alanı drilosphere (solucan salgıları tarafından etkilenen toprak parçaları) sistemi olarak bilinir. Solucan vücudu hem içten hem dıştan metabolik süreçler sistemidir; yani içten ve dıştan mukus üretimi, solunum, bağırsak geçidi ve azot atılımı vardır (Brown et al., 2000). Solucanlar, biseksüel hayvanlardır ve çok hızlı çoğalırlar (Sinha et al., 2008) . Solucanlar daha önceleri toprak yapısı ve verimliliğinin sağlanmasına yardımcı olmak için arazi iyileşmesi veya optimal altı toprakların rehabilitasyonunun sağlanması kapsamında kullanılmıştır (Edwards and Bohlen, 1996; Butt et al., 2004). Solucanların organik maddeler ile etkileşimleri vardır. Bu solucanlar en güçlü toprak mikroplarını etkileyebilir, boyutunu ve mikrobiyal biyokütle dağılımını değiş̧irebilir (Bohlen et al., 2004). Solucanlar toprak yapısını, topraktaki bitki besin elementlerinin bitkiler tarafından kolay alınabilmesi üzerinde etkilidir(Lavelle et al., 2004). Parthasarathi et al., (2008) İran'da yaptıkları bir araştırmada solucan gübresi uygulaması sonucunda toprak gözenek yapısı, su tutma kapasitesi, katyon değiştirme kapasitesi, organik karbon miktarı, alınabilir azot, fosfor, potasyum, mikrobiyal biyomass aktivitesi artarken; hacim ağırlığı, tane yoğunluğu, $\mathrm{pH}$ ve elektriksel iletkenlik değerlerinin ise azaldığı tespit edilmiştir. Pek çok farklı araştırmacı solucan gübresinin bitki büyümesi, ve biyomas oluşturması ve toprak koruması üzerinde solucan gübresinin faydalı olduğunu belirtmişlerdir (Vasudevan and Sharma, 1997; Riggle and Holmes, 1994; Edwards, 1995; Pashanasi et al., 1996; Hidalgo, 1999; Kaviraj, 2003). Onların hareketleri tünelleri oluştururken beslenme faaliyetleri organik madde ve mineral agrega oluşturur. Her ikisi de solucan öldükten sonra uzun bir ana kadar devam edebilir. Solucanlar kendi fizyolojisini etkilemeden kendi ağır metal gibi metallerin yüksek konsantrasyonlarını bio-accumulate (biyo birikme) edebilir (Sinha et al., 2008).

Solucanların bazı özel türleri vücutlarında metalleri düzenleyen özgüllük (spesifiteye) ve kapasiteye sahiptir. Bu nedenle kullanılacak olan toprakta metal içeriğini azaltır (Hopkin, 1989). Solucanlar topraktan polisiklik aromatik hidrokarbonlar (PAH) gibi lipofilik organik mikro kirleticileri, ağır metalleri ve pestisitleri kaldırmak için bulunmuştur (Contreras-Ramos et al., 2006; Sinha et al., 2008). Yapılan çalışmalar sonucunda solucanların kirlenmiş toprakta bulunan kadmiyum (Cd), civa $(\mathrm{Hg})$, kurşun $(\mathrm{Pb})$, bakır $(\mathrm{Cu})$, mangan $(\mathrm{Mn})$, kalsiyum $(\mathrm{Ca})$, demir (Fe) ve çinko (Zn) gibi ağır metalleri bünyelerinde biriktirdikleri belirlenmiştir (Hartensein et al., 1980). Avusturalya'da yapılan bir araştırmada $\mathrm{Cu}$ ve $\mathrm{Zn}$ kirliliğinin olduğu topraklara aşılanan solucan dokularında bakırın biriktiği ve bakır kirliliği arttıkça genç bireylerin yaşam yüzdelerinin azaldığı belirlenmiştir (Malley et al., 2006).Topraktaki ağır metal kirlenmesini iyileştirmek için dünyada geçmişten günümüze solucanların kullanıldığı birçok çalışma olmuştur: Sinha et al., 2002; Daia et al., 2004; Shahmansouri et al., 2005; Munroe 2007; Hickman and Reid 2008; lordache and Borza, 2012). Bu çalışmaların çoğunda topraktaki ağır metallerin temizlenmesinde ve toprak kalitesinin iyileştirilmesinde solucanların kullanılabileceği belirtilmektedir.

\section{Sonuç ve Öneriler}

Biyoremediasyon ve fitoremediasyon ile yapılan çalışmalarda solucanlar ve bitkiler ile doğal süreç içerisinde olumlu ya da olumsuz sonuçlar alınabilmektedir. Sonuçlar; alanın iklim koşullarına, toprak içerisindeki ağır metal oranına, toprak özelliklerine, bitki ya da organizmanın uyum sağlamasına bağı olarak değişebilir. Öncelikli çalışmalar yapılırken envanter çalışması ile alanlar, kullanılacak türler belirlenmeli ve uygulanacak yöntemler ortaya konulmalıdır. Kullanılacak bitki çeşitleri ve organizma çeşitleri bünyesinde küçük alanda elde edilecek veriler doğrultusunda çalışmalar geniş alana yayılmalıdır. Gelişmekte olan ülkelerde su ve toprağın ağır metaller tarafından kirlenmesini önlenmek ve azaltmak için yeni stratejilerin ortaya konulması son derece önemlidir. Bu nedenle dünyada yapılan çalışmalar incelendiğinde bu konuda Vetiver çimi bitkisi kökleri bazı ağır metallere çok iyi tolerans göstermiş, kirliliğin çevre alanlara dağılmasını önleyen ucuz ekonomik bir sistem olduğu ortaya konulmuştur. Türkiye'de Vetiver çimi bitkisinin bu yeteneğini doğrulamak için Vetiver köklerinden ayrıntılı, çeşitli ve daha çok deney alanları oluşturulmalıdır. Ayrıca bitkinin öldükten sonraki süreçte yapraklarında biriktirdiği ağır metallerin çevreye zarar vermeden nasıl ve hangi işlemlerle bertaraf edileceği açıkça belirlenmelidir. Solucanlar ile yapılan çalışmaların literatür raporlarında solucan bünyesinin bazı ağır metalleri kendi içerisinde parçalayıp kendi sistemi ile yok ettiği ortaya konulmuştur. Ağır metallerin geri dönüşümü için tarım alanlarını iyileştirme 
çalışmalarında solucanlar aktif bir şekilde kullanılmaktadır. Bu çalışmalarda uygun solucan türlerinin hangi toprak özelliklerine, iklim koşullarına adapte olabileceği konusunda uygunluğun tespit edilmesi gerekir. Öncelikli toprak küçük bir alanda parsellenmeli ve organizma çoğalması izlenmelidir. Türkiye'de yeni olarak solucanlar ile oluşturulan vermikompost yöntemi tarım alanlarında olumlu sonuçlar sonunda kullanılmalıdır. Ağır metaller ile ilgili toprak iyileştirme çalışmaları solucanlar üzerinde Türkiye'de yok denecek kadar azdır. Bu konuyla ilgili farklı iklim ve toprak özelliklerine sahip ve ağır metallerce kirlenmiş alanlarda çalışmalar yapılmalı ve solucanların ağır metallerin temizlenmesi üzerindeki etkisi ortaya konulmalıdır.

Sonuç olarak toprağın iyileştirilmesi geleceğe bir mirastır. Bu nedenle toprağın yapısını bozmadan akılcı çözümler ile ekonomik atılımlar yapılması kirlenmiş alanların rehabilitasyonu ve tüm alanların sürdürülebilir kullanılması ülkelerin geleceği için son derece önemlidir.

\section{Kaynaklar}

Aksorn, E. and Chitsomboon, B. (2013). Bioaccumulation of heavy metal uptake by two different Vetiver grass (Vetiveria zizanioides and Vetiveria nemoralis) species. African Journal of Agricultural Research, 8(24): 3166-3171.

Antiochia, R., Campanella, L., Ghezzi, P. and Movassaghi, K. (2007). The use of vetiver for remediation of heavy metal soil contamination. Anal Bioanal Chem, 388: 947-956.

Arthur, E., Rice, P., Rice, P., Anderson, T., Baladi, S., Henderson, K. and Coats, J. (2005). Phytoremediation: An overview. Crit. Rev. Plant Sci., 24: 109-122.

Aybar, M., Bilgin, A. ve Sağlam, B. (2015). Fitoremediasyon Yöntemi Ile Topraktaki Ağır Metallerin Giderimi. Doğal Afetler ve Çevre Dergisi, 1(1-2): 59-65.

Baş, A.L. ve Demet, Ö. (1992). Çevresel Toksikoloji Yönünden Bazı Ağır Metaller. Çevre Dergisi, 5: 4246.

Bohlen, P.J., Parmalee, R. and Blair, J. (2004). Integrating the effects of earthworms on nutrient cycling across spatial and temporal scales. In C. Edwards, ed. Earthworm Ecology, 161-180.

Boopathy, R. (2000). Factors limiting bioremediation Technologies. Bioresource Technology, 74: 6367.

Brown, G.G., Barois, I. and Lavelle, P. (2000). Regulation of soil organic matter dynamics and microbial activity in the drilosphere and the role of interactions with other edaphic functional domains. Eur. J. Soil Biol., 36(3): 98-177.

Butt, K.R., Lowe, C.N., Frederickson, J., and Moffat, A.J. (2004). The development of sustainable earthworm populations at Calvert landfill site. UK. Land Degrad Dev., 15: 27-36.

Chen, H.M., Zheng, C.R., Tu, C. and Shen, Z.G. (2000). Chemical methods and phytoremediation of soil contaminated with heavy metals. Chemosphere, 41(1-2): 229-234.

Chowdhury, S., Bala, N.N. and Dhauria, P. (2012). Bioremediation-A Natural Way For Cleaner Environment. International Journal of Pharmaceutical, Chemical and Biological Sciences, 2(4): 600-611.

Cındık, Y. (2012). Trabzon İli Maçka İlçesi Esiroğlu Beldesinde Erozyan Açık Şev Alanlarda Vetiver grass (Vetiveria zizanioides (Linn.) Nash ) Bitkisinin Erozyon Önleme Olanaklarının Araştırılması. Yüksek Lisans Tezi, KTÜ Fen Bilimleri Enstitüsü, Trabzon.

Contreras-Ramos, S.M., Alvarez-Bernal, D. and Dendooven, L. (2006). Eisenia fetida Increased Removal of Polycyclic Aromatic Hydrocarbons (PAHs) from Soil. Environmental Pollution, Elsevier Pub., 141: 396-401.

Cunnigham, S.D., Anderson, T.A., Schwab, P. and Hsu, F.C. (1996). Phytoremediation of soils contaminated with organic pollutants. Adv. Agronomy, 56: 55-114. 
Daia, J., Becquerb, T., Rouillerc, J.H., Reversata, G., Bernhard-Reversata, F., Nahmania, J. and Lavellea, P. (2004). Heavy metal accumulation by two earthworm species and its relationship to total and DTPA-extractable metals in soils. Soil Biology \& Biochemistry, 36: 91-98.

Damodaran, D., Suresh, G. and Mohan B, R. (2011). Bioremediation of Soil by Removing Heavy Metals Using Saccharomyces Cerevisiae. 2nd International Conference on Environmental Science and Technology, Singapore.

Danh, L.T., Truong, P., Mammucari, R., Tran, T. and Foster, N. (2009). Vetiver grass, Vetiveria zizanioides: A Choice Plant For Phytoremediation of Heavy Metals And Organic Wastes. International Journal of Phytoremediation, 11: 664-691.

Edwards, C.A. (1995). Historical overview of vermicomposting. Biocycle, 36(9): 56-8.

Edwards, C.A. and Bohlen, C.J. (1996). Biology and Ecology of Earthworms. 3rd ed. London: Chapman \& Hall.

EPA. (2001). Brownfields Technology Primer: Selecting and Using Phytoremediation for Site Cleanup. USEPA (United States Environmental Protection Agency), Washington DC.

Etim, E.E. (2012). Phytoremediation and Its Mechanisms: A Review. International Journal of Environment and Bioenergy, 2(3): 120-136.

Evanko, C.R. and Dzombak, D.A. (1997). Remediation of Metals-Contaminated Soils and Groundwater. Technology Evaluation Report, E Series: TE-97-01, Ground-Water Remediation Technologies Analysis Center.

Frick, C.M., Farrell, R.E. and Germida, J.J. (1999). Assessment of Phytoremediation as an In-Situ Technique for Cleaning Oil-Contaminated Sites. Department of Soil Science University of Saskatchewan, Saskatoon, SK Canada.

Garbisu, C. and Alkorta, I. (2003). Basic concepts on heavy metal soil bioremediation. The European Journal of Mineral Processing and Environmental Protection, 3(1): 58-66.

Gerrard, M.A. (2008). The ability of Vetiver grass to act as a primary purifier of waste water; an answer to low cost sanitation and fresh water pollution. The Vetiver Network International, Texas.

Hamutoğlu, R., Dinçsoy, A.B., Cansaran-Duman, D. ve Aras, S. (2012). Biyosorpsiyon, adsorpsiyon ve fitoremediasyon yöntemleri ve uygulamaları. Türk Hijyen ve Deneysel Biyoloji Dergisi, 69(4): 235-53.

Hartenstein, R., Neuhauser, E.F. and Collier, J. (1980). Accumulation of heavy metals in the earthworm E. foetida. J Environ Qual, 9: 23-26.

Henry, J.R. (2000). An Overview of the Phytoremediation of Lead and Mercury. U.S. Environmental Protection Agency Office of Solid Waste and Emergency Response Technology Innovation Office Washington, D.C.

Hickman, Z.A. and Reid, B.J. (2008). Earthworm assisted bioremediation of organic contaminants. Environ. Int. 34: 1072-1081.

Hidalgo, P. (1999). Earthworm castings increase germination rate and seedling development of cucumber. Mississippi Agricultural and Forestry Experiment Station, Research Report; 22(6).

Hopkin, S.P. (1989). Ecophysiology of Metals in Terrestrial Invertebrates. London, Elsevier.

lordache, M. and Borza, I. (2012). The bioremediation potential of earthworms (Oligochaeta: Lumbricidae) in a soil polluted with heavy metals. Journal of Food, Agriculture \& Environment 10(2): 1183-1186.

İleri, R. (2000). Çevre Biyoteknolojisi. 1. Baskı. Adapazarı: Değişim Yayınları: 501-22. 
Jian, C., Yang, Z., Su, Y., Han, F.X. and Monts, D.L. (2011). Phytoremediation Of Heavy Metal/Metalloid-Contaminated Soils. In Contaminated Soils: Environmental Impact, Disposal and Treatment., Ed: Robert V. Steinberg, Chapter 6, Nova Science Publishers, Inc., NY.

Kaviraj Sharma, S. (2003). Municipal solid waste management through vermicomposting employing exotic and local species of earthworms. Bioresource Technology, 90: 169-73.

Khan, A.G. (2003). Vetiver grass as an Ideal Phytosymbiont for Glomalian Fungi for Ecological Restoration of Heavy Metal Contaminated Derelict Land. Proceedings of Third Internatioal Vetiver Conference (ICV-3), Guangzhou, China.

Kocaer, F.O. ve Başkaya, H.S, (2003). Metallerle Kirlenmiş Toprakların Temizlenmesinde Uygulanan Teknolojiler. Uludağ Üniversitesi Mühendislik-Mimarlık Fakültesi Dergisi, 8(1): 121-131.

Lai, H.Y. and Chen, Z.S. (2004). Effects of EDTA on solubility of cadmium, zinc, and lead and their uptake by rainbow pink and vetiver grass. Chemosphere 55: 421-430.

Lavelle, P., Charpentier, F., Villenave, C., Rossi, J.-P., Derouard, L., Pashanasi, B., Andr'e, J., Ponge, J.F. and Bernier, N. (2004). Effects of earthworms on soil organic matter and nutrient dynamics at a landscape scale over decades. In C. Edwards, ed. Earthworm Ecology. Boca Raton, FL: CRC Press LLC.

Malik, A. (2006). Environmental Microbiology: Bioremediation. National Science Digital Library, http://nsdl.niscair.res.in/jspui/bitstream/123456789/659/1/Bioremediation.pdf, Erişim Tarihi: 2.06.2016.

Malley, C., Nair, J. and Ho, G. (2006). Impact of heavy metals on enzymatic activity of substrate and on composting worms Eisenia fetida. Bioresource Technology 97: 1498-1502.

Marques, A.G.C., Rangel, A.O.S.S. and Castro, P.L. (2009). Remediation of Heavy Metal Contaminated Soils: Phytoremediation as a Potentially Promising Clean-Up Technology. Critical Reviews in Environmental Science and Technology, 39(8): 622-654.

Montinaro, S., Concas, A., Pisu, M. And Cao, G.,(2012). Remediation of Heavy Metals Contaminated Soils by Ball Milling. Chemical Engineering Transactions, 28: 187-192.

Moosavi, S.G. and Seghatoleslami, M.J. (2013). Phytoremediation: A review. Adv. Agri. Biol. 1(1): 511.

Mudhiriza, T., Mapanda, F., Mvumi, B.M., and Wuta, M. (2015). Removal of nutrient and heavy metal loads from sewage effluent using vetiver grass, Chrysopogon zizanioides (L.) Roberty. Water SA, 41(4): 457-463.

Munroe, G. (2007). Manual of On-farm Vermicomposting and Vermiculture. Publication of Organic Agriculture, Centre of Canada, Nova Scotia.

NRC. (1993). Vetiver Grass: A Thin Green Line against Erosion, National Research Council Board on Science and Techonology for International Development. National Academy Press, Washington, D.C.

Okcu, M., Tozlu, E., Kumlay, A.M. ve Pehluvan, M. (2009). Ağır Metallerin Bitkiler Üzerine Etkileri. Alınteri, 17(B): 14-26.

Okrent, D. (1999). On intergenerational equity and its clash with intragenerational equity and on the need for policies to guide the regulation of disposal of wastes and other activities posing very long time risks. Risk Analysis, 19: 877-901.

Özay, C. ve Mammadov, R. (2013). Ağır Metaller ve Süs Bitkilerinin Fitoremediasyonda Kullanılabilirliği. BAÜ Fen Bil. Enst. Dergisi, 15(1): 67-76.

Parthasarathi, K., Balamurugan, M. and Ranganathan, L.S. (2008). Influence of vermicompost on the physico-chemical and biological properties in different types of soil along with yield and 
quality of the pulse crop-blackgram. Iran. J. Environ. Health. Sci. Eng., 2008, Vol. 5, No. 1, pp. 51-58.

Pashanasi, B., Lavelle, P., Alegre, J. and Charpentier, F. (1996). Effect of the endogeic earthworm, Pontoscolex corethrurus on soil chemical characteristics and plant growth in a low-input tropical agroecosystem. Soil Biology \& Biochemistry, 28(6): 801-8.

Pilon-Smits, E.A.H. and Freeman, J.L. (2006). Environmental Cleanup using Plants: Biotechnological Advances and Ecological Considerations. Frontiers in Ecology and the Environment, 4: 203210.

Riggle, D. and Holmes, H. (1994). New herizons for commercial vermiculture. Biocycle, 35(10): 58-62.

Roongtanakiat, N. (2009). Vetiver Phytoremediation for Heavy Metal Decontamination. PRVN Tech. Bull. No. 2009/1. ORDPB, Bangkok, Thailand.

Roongtanakiat, N. and Chairoj, P. (2001). Uptake Potential of Some Heavy Metals by Vetiver Grass. Kasetsart J. (Nat. Sci.), 35: 46-50.

Salt, D.E., Blaylock, M., Kumar, N., Dushenkov, V., Ensley, B.D., Chet, I. and Raskin, I. (1995). Phytoremediation: A Novel Strategy for the Removal of Toxic Metals from the Environment Using Plants. Bio/technology, 13: 468-474.

Shahmansouri, M.R., Pourmoghadas, H., Parvaresh, A.R. and Alidadi, H. (2005). Heavy Metals Bioaccumulation by Iranian and Australian Earthworms (Eisenia fetida) in the Sewage Sludge Vermicomposting. Iranian J Env Health Sci Eng, 2(1): 28-32.

Sharma, S. (2012). Bioremediation: Features, Strategies and applications. Asian Journal of Pharmacy and Life Science, 2(2): 202-213.

Sinha, R.K., Bharambe, G. and Ryan, D. (2008). Converting wasteland into wonderland by earthworms-a low-cost nature's technology for soil remediation: A case study of vermiremediation of PAHs contaminated soil. Environmentalist, 28: 466-475.

Sinha, R.K., Herat, S., Agarwal,S., Asadi, R. and Carretero, E. (2002). Vermiculture Technology for Environmental Management: Study of Action of Earthworms Elsinia foetida, Eudrilus euginae and Perionyx excavatus on Biodegradation of Some Community Wastes in India and Australia; The Environmentalist, U. K., 22(2): 261-268.

Sinha, R.K., Valani, D., Sinha, S., Singh, S. and Herat, S. (2009). Bioremediation of Contaminated Sites: A Low-Cost Nature's Biotechnology for Environmental Clean Up By Versatile Microbes, Plants \& Earthworms. In: Solid Waste Management and Environmental Remediation, Chapter 1, Ed: Timo Faerber and Johann Herzog, Nova Science Publishers, Inc.

Suciu, I., Cosma, C., Todică, M., Bolboacă, S.D. and Jäntschi, L. (2008). Analysis of Soil Heavy Metal Pollution and Pattern in Central Transylvania. International Journal of Moleculer Science, 9: 434-453.

Şener, Ş. (2010). Çevre için Jeoloji; Ağır Metallerin Çevresel Etkileri. SDUGEO, 1 (3): 33-35.

Truong, P. N. and Baker, D. (1998). Vetiver Grass System for Environmental Protection. Pacific Rim Vetiver Network, Technical Bulletin No. 1998/1. Royal Development Projects Protection, Office of the Royal Development Projects Board, Bangkok, Thailand.

Troung, P., Hedrick, J. and Searle, G. (2006). Vetiver Grass for Environmental Protection and Landscaping in Australia and around the World. The Fourth International Conference on Vetiver (ICV-4), Vetiver and People, Caracas, Venezuela.

Türkoğlu, B. (2006). Toprak Kirlenmesi ve Kirlenmiş Toprakların Islahı. Yüksek Lisans Tezi, Çukurova Üniversitesi Fen Bilimleri Enstitüsü, Adana.

USEPA. (2000). Introduction to Phytoremediation. EPA 600/R-99/107. U.S. Environmental Protection Agency, Office of Research and Development, Cincinnati, $\mathrm{OH}$. 
Usman, A.R., Kuzyakov, Y., Lorenz, K. and Stahr K. (2006). Remediation of a soil contaminated with heavy metals by immobilizing compounds. J. Plant Nutr. Soil Sci., 169: 205-212.

Vasudevan, P. and Sharma, S. (1997). Adoption of biofertilizers by farmers: some experiences. Proceedings at Int Conference on Application of Biotechnology in Biofertilizers and Biopesticides, DBEB, IIT Delhi.

Yılmaz, M. (2015). Türkiye'de kırsal nüfusun değişimi ve illere göre dağılımı (1980-2012). Doğu Coğrafya Dergisi, 20(33): 161-187.

Yurdakul, i. (2015). Kirletilmiş Topraklarda ve Sularda Bitkisel İyileştirme Teknikleri ve Önemi. Türkiye Tarımsal Araştırmalar Dergisi, 2: 55-62. 